\title{
Exposure to Barbie: Effects on thin-ideal internalisation, body esteem, and body dissatisfaction among young girls
}

\begin{abstract}
Barbie doll ownership is high among girls in early primary school. It has been suggested that exposure to Barbie impacts negatively on body image. The present study sought to investigate the effect of exposure to Barbie on young girls' thin-ideal internalisation, body esteem, and body dissatisfaction. Participants were 160 girls (aged 5 to 8 years) from Adelaide, South Australia. They were randomly allocated one of three Barbie conditions (physical engagement, physical observation, print observation) or to a control toy. Results indicated that exposure to Barbie, irrespective of format, led to higher thin-ideal internalisation than exposure to the control, but had no impact on body esteem or body dissatisfaction. This suggests that interacting with Barbie may encourage girls in early primary school to adopt a preference for a thin body, but with no immediate effect on body image. The long-term impact of Barbie exposure on body image remains unknown.
\end{abstract}

Keywords: Body image; young girls; Barbie doll; thin-ideal internalisation; body esteem; body dissatisfaction 
Body image concerns disproportionately affect women and girls over their male counterparts in many different Western societies (Ambrosi-Randic, 2000; Muth \& Cash, 1997; Tatangelo \& Ricciardelli, 2013). Although there are likely to be numerous societal and developmental factors contributing to this disparity, a number of commentators (e.g., Dittmar, 2012; Tiggemann, 2011) have suggested that Barbie dolls, which are sold in 150 countries worldwide (Mattel, 2016), may promote internalisation of the thin ideal in young girls. Although thin-ideal internalisation has been demonstrated in girls as young as 5 years (e.g., Birbeck \& Drummond, 2009; Hayes \& Tantleff-Dunn, 2010), the link between Barbie doll exposure and thin-ideal internalisation has yet to be established. Furthermore, the small amount of experimental research into the link between acute Barbie exposure and body image has produced mixed findings (Anschutz \& Engels, 2010; Dittmar, Halliwell, \& Ive, 2006; Jellinek, Myers, \& Keller, 2016). The present study sought to examine the extent to which exposure to Barbie dolls influences internalisation and body image among 5- to 8-year old Australian girls. A second question was whether playing with a Barbie doll in a functional manner would lead to more positive body image outcomes relative to other forms of Barbie exposure (e.g., viewing images of Barbie).

Barbie doll ownership is very common among young girls in many different countries, with an estimated 59\% ownership rate among U.S. 4- to 7-year olds (Sherman \& Zurbriggen, 2014), and over 80\% ownership rate among 6- to 9-year old Australian girls (Slater \& Tiggemann, 2016). Barbie's high level of market penetration has led to the establishment of Barbie as an iconic representation of the female ideal (e.g., Kuther \& McDonald, 2004; Wright, 2003). During her history of over 50 years, Barbie's hair, facial features, clothing, accessories, and careers have regularly changed, yet with the exception of a slight decrease in her bust and a small increase in hip width in the 1990s, her figure has remained largely stable throughout this period (Lind \& Brzuzy, 2008; Urla \& Swedlund, 2007). Barbie has a 5-inch 
bust, a 31/4 inch waist, and 5\%/16 inch hips (Mattel, 2012), which in adult women would translate to a 39-inch bust, an 18-inch waist, and 33-inch hips (Lind \& Brzuzy, 2008). Research emphasises the fact that Barbie's physical proportions do not realistically reflect the measurements of real women and are essentially unattainable (Brownell \& Napolitano, 1995; Norton, Olds, Olive, \& Dank, 1996).

As both an unrealistic symbol of ideal feminine beauty and a toy marketed at young girls, Barbie has attracted much criticism (e.g., Dittmar et al., 2006; Pedersen \& Markee, 1991; Smolak, 2011; Turkel, 1998; Walter, 2011). This criticism is founded in the belief that playing with Barbie can lead to internalisation of the thin ideal and subsequent body image concerns among young girls (Thompson, Heinberg, Altabe, \& Tantleff-Dunn, 1999). While it is commonly accepted that play in general contributes to the internalisation of ideals and values (Sutton-Smith, 1997; Thompson et al., 1999), and that internalisation of thin ideals negatively impacts on body image (Clark \& Tiggemann, 2008; Dittmar \& Howard, 2004), the connections between Barbie and thin-ideal internalisation are yet to be empirically established.

Research on thin-ideal internalisation in girls younger than 8 years has been limited, but there are indications that girls in the first years of school may be influenced by the body shape of attractive characters (Harrison, 2000) and that they hold body ideals at the leaner end of the spectrum (Harrison \& Hefner, 2006). Pre-schoolers (age 4 and under) have been shown to prefer thinner body types over larger body types (Holub, 2008; Spiel, Paxton, \& Yager, 2012) and girls aged $3 \frac{1}{2}$ to $5 \frac{1}{2}$ years also display more positive attitudes towards thin and average shaped dolls in comparison to fat dolls (Worobey \& Worobey, 2014). It remains unknown exactly when body dissatisfaction might develop. However, a recent systematic review reported that $20 \%$ to $70 \%$ of 3 - to 6 -year old girls experience body dissatisfaction (Tatangelo, McCabe, Mellor, \& Mealey, 2016). 
By age 6 , there is strong evidence that the desire for a thinner body is prevalent among girls (Birbeck \& Drummond, 2009; Dohnt \& Tiggemann, 2004). This desire to be thinner appears to be symptomatic of the internalisation of a thin ideal evident among 5- to 6-year old girls (Brylinsky \& Moore, 1994; Penny \& Haddock, 2007) that remains stable throughout childhood (Evans, Tovée, Boothroyd, \& Drewett, 2013; Tatangelo \& Ricciardelli, 2013), adolescence (Brown \& Slaughter, 2011; Sands \& Wardle, 2003) and adulthood (Brown \& Slaughter, 2011). Notably, the desire and preference for thinness in 6-year old girls is not seen in 6-year old boys (Ambrosi-Randic, 2000), which suggests that society disproportionately communicates messages of thinness to girls. Although there are likely to be numerous societal contributors (e.g., media, peers), dolls emphasising thinness (e.g., Barbie, Bratz, Disney Princesses), which are marketed at young girls, may contribute to this gender disparity.

Socio-cultural theory (Thompson et al., 1999) provides an appropriate framework for understanding how girls may develop a preference for thinness. The theory emphasises the relationship between children's body image development and the culture in which they are socialised. Specifically, it suggests that shared societal beauty ideals are transmitted via various socio-cultural channels (e.g., peers, media - including toys) and then, although often unrealistic and unattainable, they are internalised by women and girls. Satisfaction or dissatisfaction with appearance is then a function of how closely individuals conform with these beauty ideals (Tiggemann, 2011).

Thompson et al. (1999) affirm that play is an important socialisation process relevant to body image and recognise that dolls such as Barbie are a means of providing children with a tactile, tangible representation of the body. Likewise, Urla and Swedlund (2007) suggest that dressing and undressing Barbie, and arranging her hair gives children a tactile and intimate sense of Barbie's body. It is therefore plausible that playing with Barbie gives young girls a 
somewhat distorted perception of a normal female body and promotes the internalisation of a thin ideal. To date, qualitative research involving 4- to 6-year old girls has found that girls of this age focus on Barbie's appearance during play and when talking about Barbie (Markee, Pedersen, Murray, \& Stacey, 1994). In addition, retrospective research has found that 10 - to 13-year old girls report viewing Barbie as a symbol of perfection and physical beauty during early childhood (Kuther \& McDonald, 2004). Not only is Barbie herself thought to communicate thin-ideal promoting messages (Thompson et al., 1999), but it is also possible that she may act as an instrument for other societal influences such as parents, peers, or the media to inadvertently promote this theme. Empirically, however, the impact of Barbie on body image among young girls is yet to be firmly established.

Three experimental studies (Anschutz \& Engels, 2010; Dittmar et al., 2006; Jellinek et al., 2016) have attempted to empirically investigate the effect of acute Barbie doll exposure on young girls' body esteem and body dissatisfaction. The first, an English study by Dittmar et al. (2006), examined the relative effects of exposure to images of the unrealistically thin Barbie, a more realistically-proportioned doll, Emme (Mendelsohn, 2003), or a no-doll control condition, on body esteem and body dissatisfaction in a sample of 5- to 8-year old girls. They found that overall body dissatisfaction scores were significantly higher for girls in the Barbie condition, relative to the other conditions. This finding suggests that Barbie may indeed negatively impact on girls' body image. Dittmar et al. (2006) also found that the effect of Barbie on body dissatisfaction was moderated by age such that relative to images of Emme and the control group, only participants in the two younger age groups (aged $5 \frac{1}{2}$ to $7 \frac{1}{2}$ ) were significantly impacted by exposure to Barbie, whereas the participants in the oldest year group (aged $7 \frac{1}{2}$ to $8 \frac{1}{2}$ ) were not.

One possible explanation for Barbie's lack of influence on participants in the oldest year level (aged $7 \frac{1}{2}$ - to $8 \frac{1}{2}$-years) may be that around this age girls' exposure to Barbie 
reaches saturation point. Consequently, girls in this age bracket may have already internalised Barbie's thin-ideal messages so that further exposure has no additional effect. This idea is congruent with Dittmar et al.'s (2006) novel finding that participants in the oldest age group displayed the greatest discrepancy between their actual body size and their ideal adult body size after exposure to Emme. While Dittmar et al. (2006) used this measure as an indication of body dissatisfaction, it could also be considered a proxy for thin-ideal internalisation. Thus girls in the oldest age group may have already internalised a thin ideal and therefore rejected the larger beauty ideal Emme conveys.

Anschutz and Engels (2010) attempted to replicate and extend the work of Dittmar et al. (2006) by conducting a similar study with 6- to 10 -year old Dutch girls $(N=117)$, but with actual dolls instead of images of dolls. The participants were asked to spend 10 minutes playing with a Barbie doll, an Emme doll, a Tyler doll (another realistically proportioned doll), or a Lego control. Contrary to Dittmar et al.’s (2006) finding, Anschutz and Engels (2010) found no main effect of exposure condition. Nor did they find any main or interaction effect with age.

Most recently, Jellinek et al. (2016) sought to examine the effect of doll type and style of clothing (revealing vs. modest) in two separate samples of 112 girls aged 6- to 8-years in the U.S. Similar to Dittmar et al. (2006) they found that playing with Barbie in comparison to a full-figured Tracey doll was associated with lower body esteem. They also found that playing with a full-figured Tracey doll decreased body size discrepancy (body dissatisfaction) relative to playing with Barbie and that clothing type did not influence this effect (Study 1). Their findings suggest that girls tended to desire an appearance closer to the doll that they interacted with. The impact of age was not examined.

Anschutz and Engels (2010) proposed that the reason for the contrast in findings between their study and that of Dittmar et al. (2006) was that their participants physically 
played with the dolls, whereas Dittmar et al.'s (2006) participants viewed images of dolls. This latter form of doll exposure may have had a similar effect as thin models in magazines, which have been shown to increase body dissatisfaction in adult and adolescent samples (Grabe, Ward, \& Hyde, 2008; Groesz, Levine, \& Murnen, 2002). Perhaps images of Barbie, like images of thin models, draw attention to and endorse the thin body shape of the subject. In contrast, the physical handling of the dolls by participants in the Anschutz and Engels (2010) study may have drawn participants' focus towards the movement of Barbie's body. However, girls also physically played with the dolls in Jellinek et al.'s (2016) study. Nevertheless, the protocols used by Dittmar et al. (2006) and Jellinek et al. (2016) had a greater appearance-focus than that used by Anschutz and Engels (2010). Girls in the study by Anschutz and Engels (2010) were also able to physically play with the dolls for a longer period of time, allowing the children to be immersed in play, and potentially drawing their focus away from Barbie's appearance.

The idea that physically handling dolls diverts attention away from their body shape is consistent with the research of Markee et al. (1994). They asked 4- to 6-year old girls about their doll preferences while they physically handled Barbie and other dolls, and found that girls did not refer to the dolls' body shapes when asked to make distinctions between them. This explanation does not suggest that physically playing with Barbie dolls completely shields girls from appearance-centric messages. On the contrary, Markee et al. (1994) found that when referring to Barbies, girls still commented on appearance-related attributes other than body shape such as hair and facial features. Rather, this explanation posits that Barbie's thin-ideal promoting messages are stronger when Barbie is depicted in a way that draws attention to her physical attributes, rather than the functionality of her body. The general protective effect of functional salience over appearance salience has been demonstrated in the broader body image literature, where body functionality has been associated with decreased 
body surveillance (Rubin \& Steinberg, 2011), increased body appreciation (Avalos \& Tylka, 2006), and more positive attitudes about the body (Franzoi, 1995). Given that a focus on physical functional ability over appearance is thought to contribute to lower body image concern (Tatangelo \& Ricciardelli, 2013), it may be that focusing on a Barbie's ability to move around and perform tasks could provide a protective effect against appearance-centric messages. This process may lessen the potential impact of Barbie on thin-ideal internalisation and body dissatisfaction.

The present study addressed the wider question explored by previous research as to whether exposure to Barbie impacts on young girls' thin-ideal internalisation and body image relative to an alternative toy, My Little Pony (a plastic white pony with a rainbow mane and tail). It also investigated the impact of different types of interactions with Barbie (physically playing with Barbie, physically observing Barbie, or viewing Barbie in printed images) to determine whether actually playing with a doll emphasising function would protect against lower body esteem, body dissatisfaction, and thin-ideal internalisation among 5- to 8-year old girls. Specifically, it was predicted that exposure to Barbie would produce greater thin-ideal internalisation and body dissatisfaction, and lower body esteem than the control condition (Hypothesis 1). Within the Barbie conditions (physical engagement, physical observation, and print observation), it was predicted that the less functional the condition, the higher the thin-ideal internalisation and body dissatisfaction, and the lower the body esteem. That is, the print observation would result in the poorest outcome, followed by physical observation, and then physical engagement (Hypothesis 2). The potential moderating influence of year level was also investigated.

\section{Method}

\section{Participants}


The participants were 160 female primary school students in the introductory years of school: Entry Year Level ( $n=56$; 5- to 6-year olds), Year 1 ( $n=49,6$ - to 7-year olds), and Year 2 ( $n=55,7$ - to 8 -year olds). Overall, the girls ranged in age from 5 years 2 months to 8 years 4 months, with a mean age of 6.71 years $(S D=0.89)$, and $84 \%$ were Caucasian. Participants were recruited from two private and five public schools, as well as from local community organisations in the Adelaide region of South Australia.

\section{Design}

This study employed a between-subjects design in which participants were randomly assigned to one of four conditions: three doll exposure conditions and one non-doll control. There were three outcome variables: thin-ideal internalisation, body esteem, and body dissatisfaction. School year level was tested as a moderating factor.

\section{Experimental Conditions}

Participants were randomly assigned to one of the four conditions: print observation, physical observation, physical engagement, and a non-Barbie physical engagement control ('My Little Pony'). In order to control for content, all conditions directed play using an identical storyline with a central character named Lily (to ensure the story's applicability to both Barbie and My Little Pony). The plot was written specifically for this study and consisted of six scenes (described in Table 1) that followed a similar storyline to that used by Dittmar et al. (2006). These scenes were presented using cardboard box puppet-style theatres with doll furniture and props, doll clothing, and backdrops depicting each scene's location (see Figure 1 for example).

Participants in the physical engagement condition were asked to act out the storyline in a form of directed play using a Barbie doll named Lily, Barbie clothing, and the scenes provided. The physical movement of the doll through the scenes was intended to mimic the 
motions of Barbie in traditional doll play and allow participants to experience movement of the doll's body.

The physical observation condition used the same scenes, props, and furniture as the previous condition, but rather than acting out the storyline themselves, participants followed the storyline by observing a series of six separate exhibits, revealed one at a time, and did not touch the Barbie doll. Each exhibit featured a motionless Barbie, Lily, who was dressed according to the scene the exhibit corresponded with. The still poses of the dolls in this condition were intended to mimic one common way girls are exposed to Barbie: motionless in packaging on commercial shelves. As the Barbie dolls in this condition did not move, they did not provide an example of doll movement, allowing for comparison with the previous physical engagement condition.

The print observation involved looking at 2D pictures of Barbie. The condition was designed to differentiate between the experience of looking at a motionless 3D Barbie doll and looking at an image of a motionless Barbie doll. This distinction is important because Barbie is regularly represented in print form on posters, on merchandise, and in the pages of books and magazines. This condition also enabled a comparison to the findings of Dittmar et al. (2006). In this condition, participants followed the storyline by looking at six photos of Lily - one of each exhibit - printed in a book. Photos of the physical observation scenes were used to ensure that the poses, scenery, props, and clothing were identical across conditions. The images featured Barbie's whole body and took up one page of a double-A4 page spread, with the text of the story on the opposite page. This condition provided no feedback about the movement of Barbie's body.

Lastly, in the control condition participants used the scenes to act out the storyline, similar to the physical engagement condition, but with a My Little Pony toy and ponyappropriate clothing, also named Lily. Like Barbie, My Little Pony is a popular brand 
marketed at girls in early primary school. Furthermore, given that ponies are animals with quite different physical dimensions to human beings, it was intended that this condition would provide no feedback to girls about either the appearance or the functionality of human female bodies.

\section{Measures}

Baseline measures were not taken in order to reduce participant load. Due to the age of participants, the questionnaire was verbally administered after exposure to their respective experimental condition. It contained measures of demographic background, thin-ideal internalisation, body esteem, and body dissatisfaction, as well as perceived experience to determine whether participants understood and enjoyed the story.

Demographic information. Participants were asked for demographic information including age, year level, favourite type of doll, whether they play with dolls at home, whether they have any Barbie dolls, and how often they usually play with Barbie.

Thin-ideal internalisation. In line with the recommendation that thin-ideal internalisation in prepubescent children be measured in terms of future (post-pubescent) body ideals (Harrison \& Hefner, 2006), the Adolescent Figure Rating Scale (Tiggemann \& Pennington, 1990) was used to measure thin-ideal internalisation. This figure-rating scale used line drawings of nine adolescent females ranging in size from very underweight to very overweight which were presented on an A3-sized card.

To gauge the extent to which girls had internalised the thin ideal, each participant was asked, "Can you point to the one who has the body shape you would most like to have when you are grown up?", similar to the measure used by Harrison and Hefner (2006) with early school-aged children. Responses were scored so that higher numbers represented greater internalisation of the thin ideal. Scores ranged from 1 to 9. 
Body esteem. Following both Dittmar et al. (2006) and Anschutz and Engels (2010), seven items from the Revised Body Esteem Scale (R-BES) (Mendelson, White, \& Mendelson, 1996) were used to measure body esteem. All items included in the R-BES were positively worded (e.g., "Kids my age like my looks" or "My weight makes me happy"). To dilute the focus on weight or body image, the questions were embedded amongst statements unrelated to appearance (e.g., "Children my age like Harry Potter"). Response options for the R-BES were 'no' (1 point), 'in between' ( 2 points), and 'yes' ( 3 points). Items were summed to produce a total body esteem score. Scores ranged from 7 to 21, with higher scores indicating higher body esteem. In the present study, internal consistency was adequate $(\alpha=$ $.70)$.

Body dissatisfaction. Body dissatisfaction was assessed using the Child Figure Rating Scale (Tiggemann \& Wilson-Barrett, 1998). This scale was presented as line drawings depicting the full bodies of nine female children ranging in size from very underweight to very overweight. This scale was presented on an A3-sized card to enable children to accurately point when making a selection. Participants were asked to point to the girl whose body shape they thought was most like theirs (current figure) and the one they would most like to have (ideal figure). Body dissatisfaction scores were calculated as the discrepancy between the selected ideal and current figures. The resulting score provided an indication of both the magnitude and direction of the discrepancy between the selections. Possible scores ranged from -8 to +8 , with positive scores indicating a desire to be thinner and negative scores indicating a desire to be larger. Figure rating scales have been widely used with children as young as 5 years (Gardner, 2001; Tiggemann \& Lowes, 2002), and it has been demonstrated that children of this age are able to accurately select their body size from a figure rating scale (Gardner, Friedman, \& Jackson, 1999; Tiggemann \& Lowes, 2002; Williamson \& Delin, 2001). 
Understanding. Immediately following the final scene in the story, participants were asked an open-ended question about the story to affirm engagement with and understanding of the story ("What do you think Lily should do next?"). Because the final scene centred on the central character's preparation to attend a party, a response that followed naturally from this scenario (e.g., "she should go to the party") was coded as indicating understanding of the story.

Body mass index (BMI). All participants were asked their willingness to be weighed and have their height measured. Assenting participants $(n=147,91.9 \%)$ wore light clothing and no shoes. They were weighed to the nearest 100 grams using portable scales and measured to the nearest millimetre using a measuring tape affixed to the wall. Data were then used to calculate BMI, a widely used measure of adiposity.

Perceived experience. Upon completion of the study, participants were asked to indicate how much they enjoyed participating in the study ("I didn't like it at all", "It was ok", "I liked it very much").

\section{Procedure}

Following ethics approval by the Flinders University Social and Behavioural Research Ethics Committee, the Department for Education and Child Development, and Catholic Education South Australia, invitations to participate in the study were sent home to the parents of girls in Reception (the entry year of school in South Australia) to Year 2 at seven different schools. Children whose parents had provided their written consent to the school and who assented to participation were invited to participate in the study. Invitations to participate were also placed in various community organisations (e.g., church and shopping centre noticeboards). Twenty-one participants were recruited in this manner. Participants were tested individually in private rooms either on the school premises or at other convenient locations. This process took approximately 15 minutes per participant. 
Participants were randomly assigned to one of the four conditions using simple randomisation. The researcher then explained the task involved in the study, her intention to ask questions afterwards, and sought to confirm participants' assent to participate in the study. During the subsequent 10 minutes, the researcher read the short story and participants, depending on the condition, were asked to either (1) use a Barbie doll to physically act out the storyline; (2) view a series of exhibits, one at a time, that used a real Barbie to depict the events of the story; (3) view images of each exhibit in a story book; or (4) use a My Little Pony toy to act out the events of the story.

Following this, the girls were verbally presented with a brief questionnaire that measured the three key outcome variables as well as demographic information and perceived experience. Height and weight were then measured for assenting participants (for subsequent calculation of BMI). Participants received a small eraser or novelty toy to thank them for their participation.

\section{Results}

\section{Sample Characteristics}

Demographic information for the sample is presented in Table 2. The total participant sample $(N=160)$ consisted of 56 girls in the entry school year level, 49 girls in Year 1, and 55 girls in Year 2, with a mean age of 6.71 years $(S D=0.89)$. The majority $(93.1 \%)$ of participants indicated that they owned a Barbie. No participants were excluded from the analyses, and with the exception of BMI data, which were absent for 13 girls, there were no missing data. There were no significant differences between the four experimental conditions in mean age, $F(3,156)=0.22, p=.88, \eta^{2}=.004$, BMI, $F(3,143)=1.43, p=.24, \eta^{2}=.03$, Barbie doll ownership, $\chi^{2}(3, \mathrm{n}=160)=1.07, p=.78$, story comprehension, $F(3,156)=0.51$, $p=.68, \eta^{2}=.01$, or study enjoyment, $F(3,156)=1.59, p=.19, \eta^{2}=.03$.

\section{The Effect of Condition on Thin-ideal Internalisation and Body Image}


Table 3 displays the mean scores for each outcome variable across the four different conditions. One-way between-subjects ANOVAs with LMATRIX planned comparisons were used to test Hypotheses 1 and 2. The first planned comparison examined scores in the control condition relative to scores in the combined Barbie conditions (contrast $=+3,-1,-1,-1$ ). As predicted, participants exposed to the Barbie conditions had significantly greater thin-ideal internalisation than participants exposed to the My Little Pony condition, $F(1,156)=6.37, p$ $=.01, \eta^{2}=.04$. However, the same pattern of results was not found for body esteem, $F(1$, $156)=1.08, p=.30, \eta^{2}=.007$, or body dissatisfaction scores relative to the control condition, $F(1,156)=0.01, p=.93, \eta^{2}<.001$. Thus Hypothesis 1 was partially supported (for internalisation).

Hypothesis 2 predicted that within the three experimental conditions, thin-ideal internalisation and body dissatisfaction scores would be highest in the print observation condition, the next highest in the physical observation condition, and lowest in the physical engagement condition, while the opposite would be true for body esteem. To test this, a series of pair-wise comparisons was conducted. For thin-ideal internalisation, while scores were lowest in the physical engagement condition as predicted, counter to prediction they were highest in the physical observation condition (Table 3). The pair-wise comparisons showed that there were no significant differences between the print observation and physical observation conditions, $F(1,156)=2.15, p=.15, \eta^{2}=.01$, the physical engagement and print observation conditions, $F(1,156)=0.17, p=.69, \eta^{2}=.00$, or the physical observation and physical engagement conditions, $F(1,156)=3.50, p=.06, \eta^{2}=.02$, although the latter difference was approaching significance. There were also no significant pair-wise differences between conditions for either body esteem, $F(1,156)=0.007, p=.93, \eta^{2}<.001 ; F(1,156)=$ $0.12, p=.73, \eta^{2}=.001 ; F(1,156)=0.18, p=.67, \eta^{2}=.001$, respectively, or body dissatisfaction, $F(1,156)=0.08, p=.78, \eta^{2}=.001 ; F(1,156)=1.82, p=.18, \eta^{2}=.01 ; F(1$, 
$156)=2.67, p=.10, \eta^{2}=.02$, respectively. Thus, the different types of Barbie exposure did not produce significantly different internalisation, body esteem, or body dissatisfaction scores. Accordingly, Hypothesis 2 was not supported.

\section{School Year Level as a Potential Moderator}

To test moderation by age, a series of factorial ANOVAs was conducted to test the interaction between year level (Entry Year, Year 1, Year 2) and condition (Control, combined Barbie) on each of the three dependent variables. Results indicated that there was no significant interaction between year level and Barbie exposure on thin-ideal internalisation, $F(2,139)=1.31, p=.27, \eta^{2}<.001$, body esteem, $F(2,139)=0.06, p=.94, \eta^{2}<.001$, or body dissatisfaction, $F(2,139)=0.92, p=.40, \eta^{2}=.01$. Likewise, when exposure to the different Barbie conditions was examined as the independent variable, there was no significant interaction between school year level and condition on thin-ideal internalisation, $F(4,111)=1.45, p=.22, \eta^{2}=.002$, body esteem, $F(4,111)=0.69, p=.60, \eta^{2}<.001$, or body dissatisfaction, $F(4,111)=0.68, p=.61, \eta^{2}=.02$. Thus the effect of Barbie doll exposure was not moderated by age.

\section{Discussion}

The present study sought to examine whether exposure to Barbie dolls promoted higher thin-ideal internalisation and body dissatisfaction, and lower body esteem among 5- to 8-year old girls. It also investigated the potential differences between varying types of interactions with Barbie and the impact of age. The major finding is clear. Exposure to Barbie promoted internalisation of the thin ideal in this sample of young girls, regardless of whether Barbie exposure occurred from printed images, the observation of an actual Barbie, or physically playing with a Barbie. Dittmar et al. (2006) likewise showed an effect of a printed Barbie image on wanting a thinner body as an adult woman. Here no effect of age (as measured by year level) was observed. Despite the higher level of thin-ideal internalisation in 
the girls exposed to Barbie, there was no evidence in the present study that this translated into higher body dissatisfaction or lower body esteem. Nevertheless, the identification of Barbie as a contributor to childhood thin-ideal internalisation is important because once a thin ideal is acquired, it tends to remain stable into adolescence and adulthood (e.g., Brown \& Slaughter, 2011). It can also serve as a precursor to subsequent body dissatisfaction (Stice \& Shaw, 2002; Thompson et al., 1999; Wertheim, Paxton, Schutz, \& Muir, 1997) and lower body esteem (Henderson-King \& Henderson-King, 1997; Irving, 1990).

The present findings indicating no effect of Barbie exposure on body image are in line with those of Anschutz and Engels (2010), who likewise found no difference in body image outcomes for participants exposed to Barbie and those exposed to an alternative toy (Lego), and no effect of age. They are, however, counter to the findings of Dittmar et al. (2006), who found that exposure to Barbie detrimentally impacted on body image, particularly for girls in younger year levels. As the methodology of the present study closely followed that of Dittmar et al. (2006), with a similar storyline and the inclusion of a print-based depiction of Barbie, the contrasting findings are unlikely to be due to methodological differences between the studies. The sample sizes were also comparable and sufficient to detect group differences. The findings are also in contrast to Jellinek et al. (2016), who found that playing with a Barbie for three minutes impacted body esteem, and was associated with a preference for a thinner body. This difference is unlikely to be due to the ceiling effects for body esteem in the present study as a comparison of mean body esteem scores across the three previous studies indicates that the body esteem scores for our sample were similar to that of previous research. It is possible that the longer (10 minute) physical exposure to Barbie in the present study and in that of Anschutz and Engels' (2010) diverted participant attention away from immediate body image concerns. The reason for the discrepancy in findings across these studies requires 
future investigation that incorporates additional factors (e.g., cultural context, different Barbie conditions, and different lengths of play).

Such research could also provide insight into the reason Anschutz and Engels' (2010) results differed from those of Dittmar et al. (2006). The explanation proposed (and tested) in the present study was that printed visual depictions of Barbie (like Dittmar et al., 2006) would emphasise appearance more strongly and thereby lead to more detrimental body image outcomes than physical depictions (like Anschutz \& Engel, 2010). It was also thought that a physically present but motionless Barbie would lead to greater thin-ideal internalisation and poorer body image than a moving doll. However, the results of the study did not support these conjectures as the different types of Barbie exposure produced no significant differences in thin-ideal internalisation, body esteem, or body dissatisfaction scores. It is possible that girls in this age group may already be so familiar with Barbie's figure from previous experience that any exposure to Barbie triggers associations with previous exposure (in print, observation, or active play) and elicits Barbie's thin-ideal messages. Indeed, girls do see Barbie in many forms - printed on posters, merchandise, books and magazines; motionless on commercial shelves and in doll houses; and also in traditional doll play. It is also possible that our manipulation of the functional salience of Barbie's body was not sufficiently strong. Indeed, Barbie is not a particularly malleable doll and therefore her ability to allow full functional play is still limited. Promoting play with Barbie that focused on strength, coordination of stamina could have increased participants' perceptions of functionality, providing a protective effect against body dissatisfaction.

Overall, the data obtained from the body esteem measure indicated that girls were largely happy with their bodies (although many girls wanted to be slightly thinner on the body dissatisfaction measure). This perhaps suggests that exposure to Barbie, in whatever form, has no immediate impact on body image for this age group. However, it is still possible 
that different types of exposure could have differential cumulative impact over time, which would only become apparent in a longitudinal study. Continued exposure to Barbie in early childhood may lead girls to not only adopt a thin ideal but also, in combination with a variety of other thin-ideal transmitters, may prime them to more readily accept future thin-ideal promoting messages. Future research is necessary to establish this link.

The findings of the present study should be considered in light of some potential limitations. Given the age of participants, the measures utilised were deliberately simple. As such, they may have lacked some sensitivity. Nevertheless, these measures were able to adequately capture differences between conditions in the study by Dittmar et al. (2006), and their use in this study enables comparison with previous research. To reduce participant load, and consistent with previous research in this area (e.g., Anschutz \& Engels, 2010; Dittmar et al., 2006), measures were also only taken post-manipulation. It remains unknown whether thin-ideal internalisation and body image scores at baseline would have impacted upon the findings of the present study. Another important question is whether the effects observed in this study would be maintained following more naturalistic play. This study used directed play, but in reality, girls generally dictate their own interaction with Barbie. They may also play with her for longer periods of time, and so the question of how longer exposure would impact on thin-ideal internalisation and body image is also relevant. This study also focused exclusively on girls. However, the internalisation of unrealistic beauty ideals is also relevant for boys. Consequently, future research could assess whether unrealistically proportioned (e.g., excessively muscular) action toys or male dolls encourage boys to internalise male physical ideals.

Notwithstanding these limitations, the fact that thin-ideal internalisation was measurably higher after just one exposure to Barbie raises the question of whether this effect would be amplified over multiple Barbie exposures, as occurs in naturalistic settings. Another 
question concerns the effect of other doll types. Girls in this study mentioned alternative dolls such as 'Bratz' and 'Monster High' dolls, both of which are highly sexualized, have thinner waists than Barbie, and highly accentuated hips, breasts, and lips, and thus may be potentially more detrimental for body image among young girls. Future research could therefore establish whether such dolls have a similar or more extreme effect on thin-ideal internalisation and body image than the Barbie. A new Barbie Fashionisatas line (Libby, 2016) has been in stores since March 2016 introducing Barbie in four different body types (petite, tall, curvy and original). The potential impact of these different Barbie body types remains unknown; however, it is hoped that this will have a more positive impact on the appearance ideals of young girls.

In sum, Barbie ownership is high among young girls and the present study suggests that exposure to Barbie (of any type) can lead to increased thin-ideal internalisation. This finding supports the claims of socio-cultural theorists, and other critics of Barbie, that Barbie does promote the thin ideal to young girls. While Barbie exposure had no immediate detrimental effect on body image, her association with increased thin-ideal internalisation raises concerns about the longer-term effects on body image. 


\section{References}

Ambrosi-Randic, N. (2000). Perception of current and ideal body size in preschool age children. Perceptual and Motor Skills, 90, 885-889. doi:10.2466/pms.2000.90.3.885

Anschutz, D. J., \& Engels, R. C. (2010). The effects of playing with thin dolls on body image and food intake in young girls. Sex Roles, 63, 621-630. doi:10.1007/s11199-010$9871-6$

Avalos, L. C., \& Tylka, T. L. (2006). Exploring a model of intuitive eating with college women. Journal of Counseling Psychology, 53, 486-497. doi:10.1037/00220167.53.4.486

Birbeck, D. J., \& Drummond, M. J. (2009). Body image and the pre-pubescent child. The Journal of Educational Enquiry, 4, 117-127.

Brown, F. L., \& Slaughter, V. (2011). Normal body, beautiful body: Discrepant perceptions reveal a pervasive 'thin ideal' from childhood to adulthood. Body Image, 8, 119-125. doi:10.1016/j.bodyim.2011.02.002

Brownell, K. D., \& Napolitano, M. A. (1995). Distorting reality for children: Body size proportions of Barbie and Ken dolls. International Journal of Eating Disorders, 18, 295-298. doi:10.1002/1098-108X(199511)18:3<295::AID-

EAT2260180313>3.0.CO;2-R

Brylinsky, J. A., \& Moore, J. C. (1994). The identification of body build stereotypes in young children. Journal of Research in Personality, 28, 170-181.

doi:10.1006/jrpe.1994.1014

Clark, L., \& Tiggemann, M. (2008). Sociocultural and individual psychological predictors of body image in young girls: A prospective study. Developmental Psychology, 44, 1124-1134. doi:10.1037/0012-1649.44.4.1124 
Dittmar, H. (2012). Dolls and action figures. In T. F. Cash (Ed.), Encyclopedia of body image and human appearance (vol. 1) (pp. 386-391). San Diego, CA: Elsevier Academic Press.

Dittmar, H., Halliwell, E., \& Ive, S. (2006). Does Barbie make girls want to be thin? The effect of experimental exposure to images of dolls on the body image of 5-to 8-yearold girls. Developmental Psychology, 42, 283-292. doi:10.1037/0012-1649.42.2.283

Dittmar, H., \& Howard, S. (2004). Professional hazards? The impact of models' body size on advertising effectiveness and women's body-focused anxiety in professions that do and do not emphasize the cultural ideal of thinness. British Journal of Social Psychology, 43, 477-497. doi:10.1348/0144666042565407

Dohnt, H., \& Tiggemann, M. (2004). Development of perceived body size and dieting awareness in young girls. Perceptual and Motor Skills, 99, 790-792. doi:10.2466/pms.99.3.790-792

Evans, E. H., Tovée, M. J., Boothroyd, L. G., \& Drewett, R. F. (2013). Body dissatisfaction and disordered eating attitudes in 7-to 11-year-old girls: Testing a sociocultural model. Body Image, 10, 8-15. doi:10.1016/j.bodyim.2012.10.001

Franzoi, S. L. (1995). The body-as-object versus the body-as-process: Gender differences and gender considerations. Sex Roles, 33, 417-437. doi:10.1007/BF01954577

Gardner, R. M. (2001). Assessment of body image disturbance in children and adolescents. In J. K. Thompson \& L. Smolak (Eds.), Body image, eating disorders, and obesity in youth: Assessment, prevention, and treatment (pp. 193-214). Washington, DC: American Psychological Association.

Gardner, R. M., Friedman, B. N., \& Jackson, N. A. (1999). Body size estimations, body dissatisfaction, and ideal size preferences in children six through thirteen. Journal of Youth and Adolescence, 28, 603-618. doi:10.1023/A:1021610811306 
Grabe, S., Ward, L. M., \& Hyde, J. S. (2008). The role of the media in body image concerns among women: A meta-analysis of experimental and correlational studies. Psychological Bulletin, 134, 460-476. doi:10.1037/0033-2909.134.3.460

Groesz, L. M., Levine, M. P., \& Murnen, S. K. (2002). The effect of experimental presentation of thin media images on body satisfaction: A meta-analytic review. International Journal of Eating Disorders, 31, 1-16. doi:10.1002/eat.10005

Harrison, K. (2000). Television viewing, fat stereotyping, body shape standards, and eating disorder symptomatology in grade school children. Communication Research, 27, 617-640. doi:10.1177/009365000027005003

Harrison, K., \& Hefner, V. (2006). Media exposure, current and future body ideals, and disordered eating among preadolescent girls: A longitudinal panel study. Journal of Youth and Adolescence, 35, 153-163. doi:10.1007/s10964-005-9008-3

Hayes, S., \& Tantleff-Dunn, S. (2010). Am I too fat to be a princess? Examining the effects of popular children's media on young girls' body image. British Journal of Developmental Psychology, 28, 413-426. doi:10.1348/026151009X424240

Henderson-King, E., \& Henderson-King, D. (1997). Media effects on women's body esteem: Social and individual difference factors. Journal of Applied Social Psychology, 27, 399-417. doi:10.1111/j.1559-1816.1997.tb00638.x

Holub, S. C. (2008). Individual differences in the anti-fat attitudes of preschool-children: The importance of perceived body size. Body Image, 5, 317-321. doi:10.1016/j.bodyim.2008.03.003

Irving, L. M. (1990). Mirror images: Effects of the standard of beauty on the self-and bodyesteem of women exhibiting varying levels of bulimic symptoms. Journal of Social and Clinical Psychology, 9, 230-242. doi:10.1521/jscp.1990.9.2.230 
Jellinek, R. D., Myers, T. A., \& Keller, K. L. (2016). The impact of doll style of dress and familiarity on body dissatisfaction in 6- to 8-year-old girls. Body Image, 18, 78-85. doi:http://dx.doi.org/10.1016/j.bodyim.2016.05.003

Kuther, T. L., \& McDonald, E. (2004). Early adolescents' experiences with, and views of, Barbie. Adolescence, 39, 39-51.

Libby, H. (2016, January 29). After 57 years, Barbie finally gets the makeover that really matters. Upworthy. Retrieved from http://www.upworthy.com/after-57-years-barbiefinally-gets-the-makeover-that-really-matters?c $=u f b 1$

Lind, A., \& Brzuzy, S. (2008). Battleground: Women, gender, and sexuality. Westport, CT: Greenwood Publishing Group.

Markee, N. L., Pedersen, E. L., Murray, C. I., \& Stacey, P. B. (1994). What role do fashion dolls play in socialization of children? Perceptual and Motor Skills, 79, 187-190. doi:10.2466/pms.1994.79.1.187

Mattel. (2012). For the record. Retrieved from http://www.barbiemedia.com/barbie_facts_for-the-record.html

Mattel. (2016). Fast facts about Barbie. Retrieved from http://www.barbiemedia.com/aboutbarbie/fast-facts.html

Mendelsohn, A. (2003). Girls love the Emme doll. Retrieved from http://www.azcentral.com/style/articles/0101emmedoll.html?\&wired

Mendelson, B. K., White, D. R., \& Mendelson, M. J. (1996). Self-esteem and body esteem: Effects of gender, age, and weight. Journal of Applied Developmental Psychology, 17, 321-346. doi:10.1016/S0193-3973(96)90030-1

Muth, J. L., \& Cash, T. F. (1997). Body-image attitudes: What difference does gender make? Journal of Applied Social Psychology, 27, 1438-1452. doi:10.1111/j.15591816.1997.tb01607.x 
Norton, K. I., Olds, T. S., Olive, S., \& Dank, S. (1996). Ken and Barbie at life size. Sex Roles, 34, 287-294. doi:10.1007/BF01544300

Pedersen, E. L., \& Markee, N. L. (1991). Fashion dolls: Representations of ideals of beauty. Perceptual and Motor Skills, 73, 93-94. doi:10.2466/pms.1991.73.1.93

Penny, H., \& Haddock, G. (2007). Anti-fat prejudice among children: The "mere proximity" effect in 5-10 year olds. Journal of Experimental Social Psychology, 43, 678-683. doi:10.1016/j.jesp.2006.07.002

Rubin, L. R., \& Steinberg, J. R. (2011). Self-objectification and pregnancy: Are body functionality dimensions protective? Sex Roles, 65, 606-618. doi:10.1007/s11199$011-9955-\mathrm{y}$

Sands, E. R., \& Wardle, J. (2003). Internalization of ideal body shapes in 9-12-year-old girls. International Journal of Eating Disorders, 33, 193-204. doi:10.1002/eat.10121

Sherman, A. M., \& Zurbriggen, E. L. (2014). "Boys can be anything”: Effect of Barbie play on girls' career cognitions. Sex Roles, 70, 195-208. doi:10.1007/s11199-014-0347-y

Slater, A., \& Tiggemann, M. (2016). [Little girls in a grown up world: Sources of sexualization and internalization of sexualization messages in 6-9 year old girls]. Unpublished raw data.

Smolak, L. (2011). Body image development in childhood. In T. F. Cash \& L. Smolak (Eds.), Body image: A handbook of science, practice, and prevention (pp. 67-75). New York: Guilford Press.

Spiel, E. C., Paxton, S. J., \& Yager, Z. (2012). Weight attitudes in 3- to 5-year-old children: Age differences and cross-sectional predictors. Body Image, 9, 524-527. doi:10.1016/j.bodyim.2012.07.006 
Stice, E., \& Shaw, H. E. (2002). Role of body dissatisfaction in the onset and maintenance of eating pathology: A synthesis of research findings. Journal of Psychosomatic Research, 53, 985-993. doi:10.1016/S0022-3999(02)00488-9

Sutton-Smith, B. (1997). The ambiguity of play. Cambridge, MA: Harvard University Press.

Tatangelo, G. L., McCabe, M., Mellor, D., \& Mealey, A. (2016). A systematic review of body dissatisfaction and sociocultural messages related to the body among preschool children. Body Image, 18, 86-95. doi:http://dx.doi.org/10.1016/j.bodyim.2016.06.003

Tatangelo, G. L., \& Ricciardelli, L. A. (2013). A qualitative study of preadolescent boys' and girls' body image: Gendered ideals and sociocultural influences. Body Image, 10, 591598. doi:10.1016/j.bodyim.2013.07.006

Thompson, J. K., Heinberg, L. J., Altabe, M., \& Tantleff-Dunn, S. (1999). Exacting beauty: Theory, assessment, and treatment of body image disturbance. Washington, DC: American Psychological Association.

Tiggemann, M. (2011). Sociocultural perspectives on human appearance and body image. In T. F. Cash \& L. Smolak (Eds.), Body image: A handbook of science, practice, and prevention (pp. 12-19). New York: Guilford Press.

Tiggemann, M., \& Lowes, J. (2002). Changes in ratings of figure preference in girls ages five to seven years. Perceptual and Motor Skills, 94, 424-424. doi:10.2466/pms.2002.94.2.424

Tiggemann, M., \& Pennington, B. (1990). The development of gender differences in bodysize dissatisfaction. Australian Psychologist, 25, 306-313. doi:10.1080/00050069008260025

Tiggemann, M., \& Wilson-Barrett, E. (1998). Children's figure ratings: Relationship to self-esteem and negative stereotyping. International Journal of Eating Disorders, 23, 83-88. doi:10.1002/(SICI)1098-108X(199801)23:1<83::AID-EAT10>3.0.CO;2-O 
Turkel, A. R. (1998). All about Barbie: Distortions of a transitional object. Journal of the American Academy of Psychoanalysis, 26, 165-177.

Urla, J., \& Swedlund, A. C. (2007). The anthropometry of Barbie: Unsettling ideals of the feminine body in popular culture. In J. Douglas, S. Earle, S. Handsley, C. Lloyd, \& S. Spurr (Eds.), A reader in promoting public health: Challenge and controversy (pp. 123-132). Milton Keynes: The Open University.

Walter, N. (2011). Living dolls: The return of sexism. London: Virago Press.

Wertheim, E. H., Paxton, S. J., Schutz, H. K., \& Muir, S. L. (1997). Why do adolescent girls watch their weight? An interview study examining sociocultural pressures to be thin. Journal of Psychosomatic Research, 42, 345-355. doi:10.1016/S00223999(96)00368-6

Williamson, S., \& Delin, C. (2001). Young children's figural selections: Accuracy of reporting and body size dissatisfaction. International Journal of Eating Disorders, 29, 80-84. doi:10.1002/1098-108X(200101)29:1<80::AID-EAT13>3.0.CO;2-O

Worobey, J., \& Worobey, H. S. (2014). Body-size stigmatization by preschool girls: In a doll's world, it is good to be "Barbie". Body Image, 11(2), 171-174. doi:http://dx.doi.org/10.1016/j.bodyim.2013.12.001

Wright, L. (2003). The wonder of Barbie: Popular culture and the making of female identity. Essays in Philosophy, 4(1), Article 3. 
Table 1

Scene-by-Scene Comparison of Story Content in Dittmar et al. (2006) and Present

Study
Dittmar et al. (2006)
Present Study

Scene 1 'Mira' wakes up, sunny

'Lily' wakes up on a sunny morning and

morning.

gets ready for the day.

Scene 2 Shopping for party outfit. Shopping for a friend's birthday present.

Scene 3 Trying on clothes in shops. Shopping for a party outfit.

Scene 4 New clothes and matching Trying on and purchasing a party outfit. shoes.

Scene 5 Supermarket on the way Shopping for and purchasing treats from home. the supermarket.

Scene 6 Getting ready for party. Getting ready for the party. 
Table 2

Demographic Information for the Sample by Condition

\begin{tabular}{|c|c|c|c|c|c|}
\hline & \multicolumn{3}{|c|}{ Barbie conditions } & \multirow{2}{*}{$\begin{array}{c}\text { Control } \\
\text { condition } \\
n=40\end{array}$} & \multirow{2}{*}{$\begin{array}{c}\text { Entire } \\
\text { sample } \\
N=160\end{array}$} \\
\hline & $\begin{array}{c}\text { Physical } \\
\text { Engagement } \\
n=40\end{array}$ & $\begin{array}{c}\text { Physical } \\
\text { Observation } \\
n=40\end{array}$ & $\begin{array}{c}\text { Print } \\
\text { Observation } \\
n=40\end{array}$ & & \\
\hline Age & $\begin{array}{c}6.78 \\
(0.87)\end{array}$ & $\begin{array}{c}6.69 \\
(0.93)\end{array}$ & $\begin{array}{c}6.63 \\
(0.89)\end{array}$ & $\begin{array}{c}6.74 \\
(0.89)\end{array}$ & $\begin{array}{c}6.71 \\
(0.89)\end{array}$ \\
\hline BMI & $\begin{array}{l}16.37 \\
(1.69)\end{array}$ & $\begin{array}{l}16.37 \\
(1.37)\end{array}$ & $\begin{array}{l}15.79 \\
(1.46)\end{array}$ & $\begin{array}{l}16.60 \\
(2.38)\end{array}$ & $\begin{array}{l}16.28 \\
(1.79)\end{array}$ \\
\hline Caucasian $n(\%)$ & $35(87.5 \%)$ & $35(87.5 \%)$ & $32(80 \%)$ & $32(80 \%)$ & $134(83.8 \%)$ \\
\hline $\begin{array}{l}\text { Barbie ownership } \\
n \text { (\% yes) }\end{array}$ & $38(95 \%)$ & $36(90 \%)$ & $37(92.5 \%)$ & $38(95 \%)$ & $149(93.1 \%)$ \\
\hline \multicolumn{6}{|l|}{$\begin{array}{l}\text { Participant source } \\
(\%)^{\text {a }}\end{array}$} \\
\hline Private school & $6(15 \%)$ & $12(30 \%)$ & $16(40 \%)$ & $20(50 \%)$ & $54(33.8 \%)$ \\
\hline Public school & $30(75 \%)$ & $23(57.5 \%)$ & $16(40 \%)$ & $16(40 \%)$ & $85(53.1 \%)$ \\
\hline Community & $4(10 \%)$ & $5(12.5 \%)$ & $8(20 \%)$ & $4(10 \%)$ & $21(13.1 \%)$ \\
\hline
\end{tabular}


Table 3

Mean (SD) Scores for Thin-ideal Internalisation, Body Esteem, and Body Dissatisfaction for the Entire Sample and by Condition

\begin{tabular}{lcccccc}
\hline & \multicolumn{2}{c}{$\begin{array}{c}\text { Barbie conditions } \\
(n=120)\end{array}$} & $\begin{array}{c}\text { Control } \\
\text { condition } \\
(n=40)\end{array}$ & $\begin{array}{c}\text { Entire sample } \\
(N=160)\end{array}$ \\
\cline { 2 - 5 } & $\begin{array}{c}\text { Physical } \\
\text { Engagement }\end{array}$ & $\begin{array}{c}\text { Physical } \\
\text { Observation }\end{array}$ & $\begin{array}{c}\text { Print } \\
\text { Observation }\end{array}$ & $\begin{array}{c}\text { Barbie } \\
\text { conditions } \\
\text { combined }\end{array}$ & & \\
\hline $\begin{array}{l}\text { Thin-ideal } \\
\text { internalisation }^{\mathrm{a}}\end{array}$ & 5.65 & 6.23 & 5.78 & $5.88^{\mathrm{d}}$ & $5.25^{\mathrm{d}}$ & 5.73 \\
Body esteem $^{\mathrm{b}}$ & $(0.92)$ & $(1.33)$ & $(1.21)$ & $(1.18)$ & $(1.86)$ & $(1.41)$ \\
& 18.88 & 18.63 & 18.68 & 18.73 & 18.23 & 18.60 \\
Body $_{\text {dissatisfaction }}{ }^{\mathrm{c}}$ & $(2.64)$ & $(2.77)$ & $(2.55)$ & $(2.64)$ & $(2.56)$ & $(2.62)$ \\
& 0.90 & 0.33 & 0.43 & 0.55 & 0.53 & 0.54 \\
\hline Range: & $(1.69)$ & $(1.47)$ & $(1.41)$ & $(1.54)$ & $(1.69)$ & $(1.41)$
\end{tabular}

a Range: 1-9, higher scores indicate greater thin-ideal internalisation; ${ }^{\mathrm{b}}$ Range: $7-21$, higher scores indicate greater body esteem. Body esteem scores were negatively skewed, reflecting a ceiling effect. Analyses of square root and logarithm transformed data produced the same results; ${ }^{\mathrm{c}}$ Range: -8 to +8 , positive scores indicate a desire to be thinner; ${ }^{\mathrm{d}}$ significant difference between conditions, $p=.01$. 


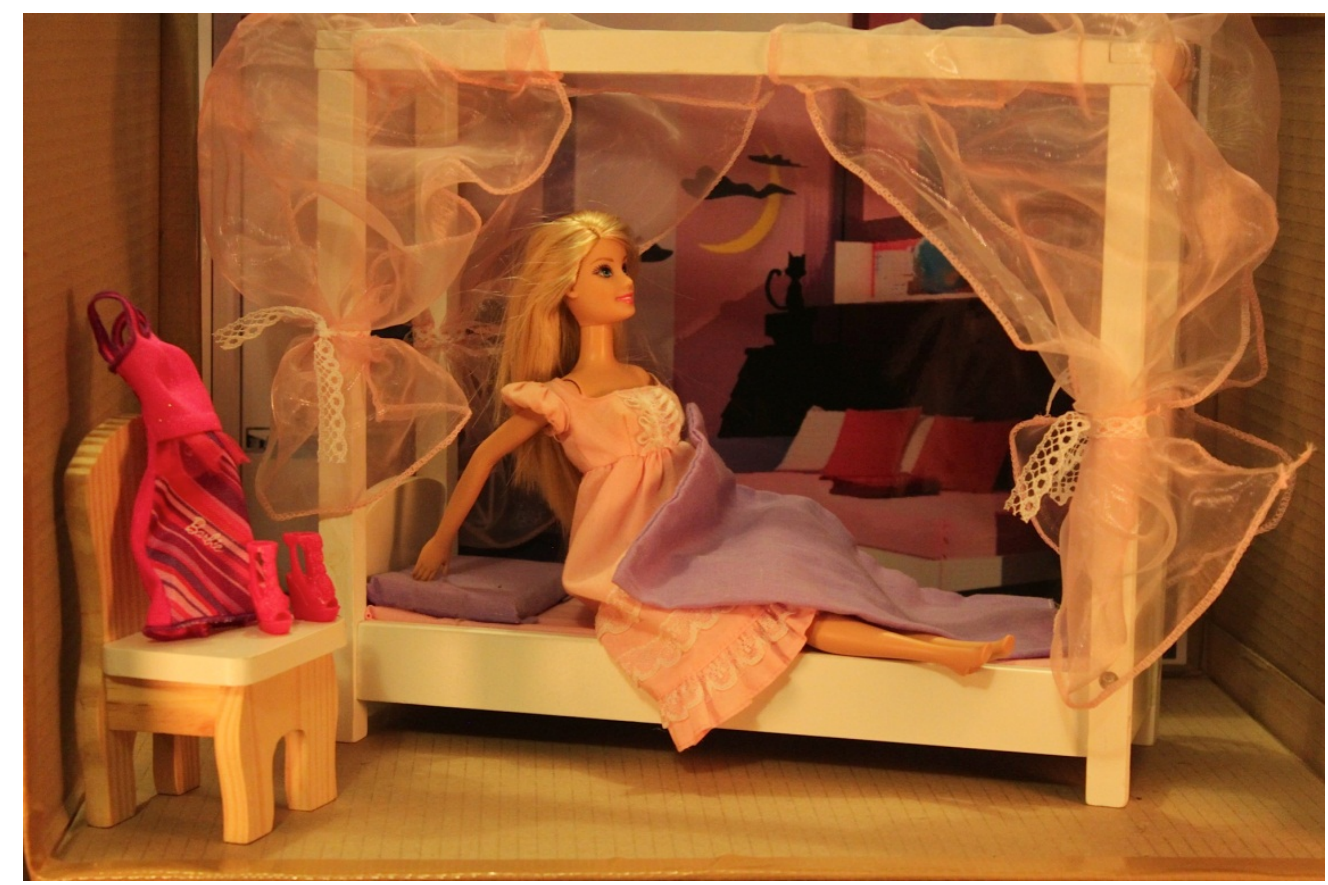

Figure 1. Scene 1 - Lily wakes up on a sunny morning and gets ready for the day. 
- The study examined the impact of different types of Barbie exposure on young girls

- Exposure to Barbie promoted thin-ideal internalisation in young girls

- Exposure to Barbie had no immediate effect on body esteem or body dissatisfaction

- The effect of Barbie was not moderated by year level (age)

- The long term effects of Barbie exposure remain unknown 


\section{Exposure to Barbie: Effects on thin-ideal internalisation, body esteem, and body dissatisfaction among young girls}

\section{Karlie Rice $^{1 *}$, Ivanka Prichard ${ }^{2 *}$, Marika Tiggemann ${ }^{1} \&$ Amy Slater ${ }^{3}$}

${ }^{1}$ School of Psychology, Flinders University, GPO Box 2100, Adelaide, South Australia

${ }^{2}$ School of Health Sciences, Flinders University, GPO Box 2100, Adelaide, South Australia

${ }^{3}$ Centre for Appearance Research, University of the West of England, UK

*Address correspondence to Karlie Rice, School of Psychology, Flinders University, karlie.rice@outlook.com or Ivanka Prichard, School of Health Sciences, Flinders University, ivanka.prichard@,flinders.edu.au, Phone: +61 882013713 